\title{
LÓGICA EM LINGUÍSTICA: O QUADRADO SEMIÓTICO E OS ESTADOS INTENCIONAIS DA PRAGMÁTICA
}

Daniel Felix Costa Jr.

\section{RESUMO}

Algumas teorias linguísticas estão repletas de termos e operadores lógicos, para exemplificar isto, escolhemos duas áreas - Semiótica e Pragmática - e um tópico em cada uma delas: o quadrado semiótico e os estados intencionais. Apesar da falta de conhecimento em Lógica não prejudicar a compreensão geral desses conteúdos, esmaece a compreensão do tratamento que é dado aos termos.

PALAVRAS-CHAVE: Quadrado Semiótico; Intencionalidade; Lógica.

\section{O formalismo dos não-formalistas - uma introdução}

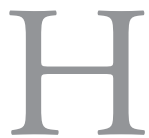

á algumas décadas tornou-se comum, dentro da Linguística, o embate entre formalistas e funcionalistas, embora, atualmente, um meio-termo entre as posturas citadas esteja tornando-se comum. A formalidade é uma característica necessária à ciência, e, portanto, abordamos aqui, o nível formal de duas correntes linguísticas, tradicionalmente tidas como não participantes da corrente formalista: a pragmática e a semiótica.

O método científico costuma basear-se nas ideias do empirismo, de percepção, observação e experiência, relacionando-se com a teoria do conhecimento, teorias de causalidade, incluindo implicaçóes da lógica. Relaçóes de causa e efeito e relações lógicas são fundamentais às disciplinas científicas, algo que não poderia ser diferente para as ciências da linguagem. 
A Lógica é uma disciplina filosófica imbuída em formular princípios e métodos de inferência, determinando em que condiçôes algumas coisas são consequências de outras. E desde a antiguidade clássica sabemos que a lógica norteia os estudos de linguagem, pois se defendia a ideia de que a linguagem era expressão do pensamento. E se o raciocínio era necessário, deveria haver regras de bem fazê-lo. Daí os conceitos de 'categorias' e 'interpretação' de cunho aristotélico que orientaram as primeiras gramáticas. Mas a lógica tem sido negligenciada na maioria dos cursos de formação linguística no Brasil, sendo limitada a discursos do tipo "tal teoria possui conceitos lógicos", ou "essa vertente é baseada na lógica clássica”. Para os que usam construçóes desse tipo, seria sensato afirmar que os seus interlocutores deveriam conhecer bem o porquê dessas afirmaçôes, mas nem sempre isso é verdadeiro.

Como é possível que afirmaçóes do tipo $\forall x(\mathrm{~A} x \rightarrow \mathrm{B} x), \square x(\mathrm{~A} x \wedge \mathrm{B} x)$, $\mathrm{T}(p) \rightarrow \mathrm{C}(\diamond p) \wedge \mathrm{D}(\neg p)$ possam estar presentes nos estudos de linguagens? $\mathrm{Na}$ verdade, alguns desses teoremas ${ }^{1}$ sempre estiveram presentes nos estudos de significado e interpretação. Os conceitos que os regem, continuam a reger disciplinas que parecem tẫo atuais e inovadoras. E dentro de uma miríade de assuntos abordados pela pragmática e pela semiótica, escolhemos apenas dois temas: a) a teoria dos estados intencionais de Searle (1983)²; e b) o quadrado semiótico, usado amplamente por Greimas e Fontanille (1993) ${ }^{3}$. O objetivo é observar de que forma os conceitos lógicos estão enredados nessas teorias, e quão intrínseco é o elo de compreensão teórica sem o conhecimento desses elementos interdisciplinares. Como meta secundária, incluímos o objetivo de expor o formalismo que há em áreas consideradas não formalistas na Linguística. Reivindica-se aqui, a menção a princípios teóricos anteriores e originários que nem sempre são lembrados nesses estudos recentes.

\section{Lógica aristotélica}

Até o advento da lógica contemporânea, com Gottlob Frege e Bertrand Russell, o domínio do pensamento aristotélico perdurou por mais de

1 Teorema é uma sentença que pode ser logicamente provada como verdadeira.

2 SEARLE, J.R. Intencionalidade. Trad. Julio Fischer, Tomás Rosa Bueno. - 2a ed. - São Paulo: Martins Fontes, 2002.

3 GREIMAS, A.J. e FONTANILLE, J. Semiótica das paixões. Trad. Maria José Rodrigues Coracini. São Paulo: Ática, 1993. 
vinte séculos no ramo de estudos lógicos. $\mathrm{Na}$ verdade, não há problemas com as formulaçôes de Aristóteles, inclusive, elas servem de parâmetro para maior parte dos estudos da lógica atual. Uma das poucas objeçóes, deve-se ao fato de que não se consegue formalizar grande parte dos raciocínios e das sentenças com a teoria greco-clássica. Não obstante, temos um conjunto de conceitos bem expostos que não se pode refutar, mas apenas limitar o seu alcance.

O conjunto de textos que compóem a lógica de Aristóteles é chamado de Órganon. Incluem-se os livros: Categorias, Da Interpretação, Analíticos Anteriores, Analíticos Posteriores, Tópicos, e Refutaçóes Sofisticas. A gramática tradicional da língua, como a conhecemos, retira daí seu esquema organizacional, suas ideias de categorização dos nomes, as noçóes de sinonímia, antonímia, termos oracionais, entre outras coisas. Segundo os lógicos antigos, todas essas questôes, que reflexionam sobre o raciocínio, deveriam ser apreendidas como instrumento para aqueles que queiram discutir sobre conhecimento ou sobre filosofia.

Basicamente, o sistema aristotélico cria regras de valoração e inferência consideradas válidas pelo raciocínio. Um dos principais meios para isto é a valoração dicotômica "verdadeiro-falso", valoração que dá origem a regras de inferência bem mais complexas.

\section{O quadrado das oposiçóes}

Sob o ponto de vista ontológico, as proposições enunciam algo sobre os seres, as valoraçóes de verdade e falsidade permitem que se possa afirmar ou negar algo de alguma coisa. $\mathrm{O}$ assunto fundamental em Da Interpretação é a linguagem e sua relação com o pensamento, como tradutora ou intérprete deste. A predicação dos seres torna-se possível através da interpretação de como a mente, ou alma na terminologia filosófica, percebe a realidade. Uma das formas de expressar um raciocínio elementar a respeito de algo é através de oposição. É certamente uma das formas mais simples de organização mental do significado, pois costumamos apreender quase tudo através de dicotomias do tipo "é" e "não é", para, a partir disto, podermos ampliar a interpretação de algum objeto a um modo tricotômico ou polidiversificado. 
Visto que a oposição é elementar à interpretação e ao significado, Aristóteles (2005, pp.86-89) ${ }^{4}$ propôs um jogo de relaçóes entre opostos, com contrários e contraditórios. Nessa perspectiva a 'afirmação' ganha um status de sentença básica e inicial de qualquer proposição, é como se todo e qualquer enunciado sobre algo fosse composto de uma ou mais afirmaçóes. Por exemplo, na seguinte sentença:

$S$ : O professor feliz chegou.

Há uma assertiva que diz 'alguém é professor', outra que diz 'alguém é feliz', e outra que diz 'alguém chegou'. Houvesse aí uma negação, ela existiria em contraposição a uma afirmação. Devido a isso o tópico 17a1 do Órganon informa que "toda afirmação terá sua própria negação oposta, tal como toda negação terá sua própria afirmação oposta" (op.cit., p.86). Então, um par composto por uma afirmativa e uma negativa é chamado de contradição. Aristóteles também alerta que as proposiçóes opostas devem enunciar sempre os mesmos sujeitos e predicados, pois essas e outras condiçóes são necessárias para se encarar as problemáticas aparentemente paradoxais dos sofistas.

As proposições negativas e afirmativas precisam de sujeitos 'universais' ou 'particulares', o exemplo dado para universais é o nome 'homem', e para particulares é o nome próprio 'Calias'. Nesse jogo de relaçóes, o tópico $17 \mathrm{~b} 1$ do Órganon fornece os elementos básicos do que se conhece por 'quadrado das oposiçôes'. Tais elementos são as proposições contrárias e proposições contraditórias. O quadrado é um artifício didático para compreensão das relaçôes lógicas fundamentais, e, embora seja de conteúdo aristotélico, não foi Aristóteles que propôs sua diagramação. Sua origem é incerta, mas quase sempre remetida aos primeiros séculos da era cristã. Ao dar prioridade aos universais, a relação de oposição pode ser feita através de algo indicado universalmente com algo indicado não universalmente, ou através de proposiçôes de caráter igualmente universais, porém uma afirmando e outra negando a predicação.

Valendo-se das proposiçóes "todo homem é branco" e "nenhum homem é branco" retiradas do Da Interpretação (op.cit., p. 86-87), compomos o quadrado representado tradicionalmente pelas letras $A, E, I$ e $O$, da seguinte for-

4 ARISTÓTELES, Órganon. Trad. Edson Bini. Bauru, SP: Edipro, 2005. 
ma: A - afirmação universal: todo homem é branco; E - negação universal: nenhum homem é branco; I - afirmação particular: algum homem é branco; $\mathrm{O}$ - negação particular: algum homem não é branco.

QUADRO 1 - Quadrado de base aristotélica com origem nos primeiros séculos da era cristã.

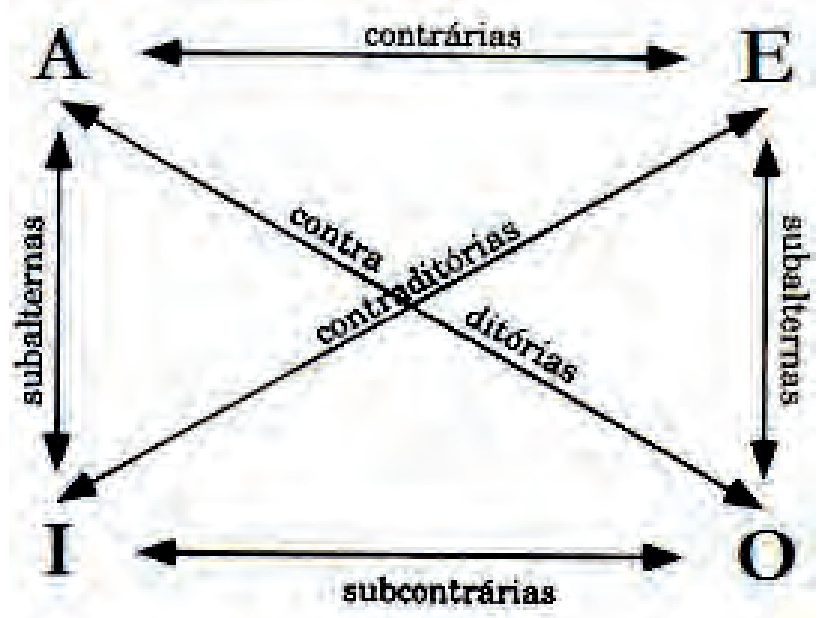

Uma proposição universal é representada pelo pronome 'todo(a)' e pela sua negativa 'nenhum(a)'. Uma proposição particular, também chamada de existencial, é representada pelo pronome 'algum(a)'. A parte superior do quadrado representa proposiçôes de caráter universal, $A$ e $E$ são consideradas contrárias entre si. Quando uma proposição afirma universalmente e a outra nega particularmente e vice-versa, significa que são proposiçóes contraditórias, logo, "todo homem é branco" e "algum homem não é branco" são contraditórias, da mesma forma que o são "nenhum homem é branco" e "algum homem é branco". Desse modo, podemos aplicar os exemplos do quadro 1 a qualquer relação de oposição, desde que se mantenham as fórmulas: ' $A$ ' representada pela proposição "todo A é B"; ' $E$ ' representada pela proposição "nenhum A é B"; 'I' representada pela proposição "algum A é B"; e 'O' representada pela proposição "algum A não é B". 


\section{Do cálculo de predicados à lógica modal}

Lembrando do primeiro polo aristotélico do quadrado das oposições, temos a sentença 'todo A é B', acrescentando a esta, sentenças com um particular qualquer, 'c é um A', logo, 'c é B'. Compõem juntas o famoso silogismo que Aristóteles descreve nos Analíticos Anteriores. Embora ainda não houvesse sido criado o alfabeto do cálculo de predicado usado na lógica clássica, esse raciocínio deu o gatilho para que gramática da lógica representasse as sentenças através de fórmulas atômicas sinalizadas por letras. Apesar do termo 'clássico' remeter à antiguidade greco-romana, é chamada de clássica a lógica de base fregeana do final do século XIX, mas que, de acordo com Mortari (2001, p. 63$)^{5}$, possui como subsistema o cálculo sentencial da lógica originada nos filósofos estóicos. Tal lógica serve de base para a matemática e para várias lógicas não-clássicas como a lógica modal alética.

Seria bastante pretensioso se pudéssemos resumir as principais regras e características da lógica clássica neste breve trabalho. Sabendo dessa impossibilidade, limitamo-nos a mencionar algumas regras e nomenclaturas lógicas que são utilizadas nas teorias linguísticas citadas aqui. A lógica sentencial, de base estóica, criou um sistema verifuncional em que sentenças ou fórmulas complexas são manipuladas com os termos 'não', 'e', 'ou', 'se... então'. Essas recebem valoraçóes $V$ para verdadeiro e $F$ para falso, de acordo com a verdade ou falsidade dos seus componentes. Uma proposição $p$ qualquer não pode receber o valor de verdade e a sua negação também ser considerada verdadeira. Se $p$ possui valor $V$, então $\neg p$ (não- $p$ ) terá valor $F$; se p tem valor $F$ então $\neg p$ terá valor $V$. Com base nessas valoraçóes simples de $p$ e $\neg p$ que se parte para sentenças complexas como as conjuntivas e disjuntivas. A conjunção significa junção ou adição de dois termos, é formada utilizando o conectivo 'e'; a disjunção tem o sentido de separação ou impossibilidade de algo possuir dois atributos ao mesmo tempo, é formada com o conectivo 'ou'; a condicional significa que o componente antecessor deve implicar no seguinte, é formulado com a expressão 'se... então'; a bicondicional indica que o que foi afirmado na expressão condicional deve valer igualmente no sentido inverso, é formada pela expressão 'se e somente se'.

5 MORTARI, Cezar A. Introdução à Lógica. São Paulo: UNESP: Imprensa Oficial do Estado, 2001. 
Essas operaçôes são o alicerce de várias lógicas, assim, "quando a lógica verifuncional é combinada à lógica dos quantificadores, o sistema formal resultante é conhecido como lógica de primeira ordem" (GOLDSTEIN et al, 2007, p. 43) ${ }^{6}$. Os principais quantificadores que são introduzidos por essa lógica são ' $\forall$ ' e ' $\square$ ' para representar universalidade e particularidade. O Órganon de Aristóteles deu as instruçóes para o que ficaria conhecido, no futuro, como quantificador universal e quantificador existencial: a afirmação universal 'todo A é B' e a afirmação existencial 'algum A é B'. Criou-se, na lógica de primeira ordem, um alfabeto para todas essas operações lógicas, incluindo caracteres para as variáveis e para as constantes. Dos sessenta e cinco caracteres, citamos a significação dos mais usados:

QUADRO 2 - Principais operadores do alfabeto da lógica de predicados de $1^{\text {a }}$ ordem.

' $\forall$ ' é o quantificador universal, lê-se 'para todo'

' $\exists$ ' é o quantificador existencial, lê-se "existe um'

' $\neg$ ' simboliza negação, lê-se 'não', também pode ser representado por ' ?

' $\wedge$ ' representa a conjunção, lê-se 'e', também pode ser representado por ' $n$ ' ou '\&'

' $v$ ' representa a disjunção, lê-se 'ou', também representado por ' $U$ '

' $\rightarrow$ ' representa a condicional, lê-se 'se... então', às vezes representado por ' $\supset$ '

' $\leftrightarrow$ ' representa a bicondicional, lê-se 'se e somente se', também representado por ‘”'.

Frege acreditava que, com a lógica de primeira ordem, grande parte dos problemas matemáticos, ou mesmo, dos problemas epistemológicos, poderia ser traduzida para uma linguagem em que se pudesse trabalhar logicamente. Partindo disto, pode-se voltar às proposiçôes que polarizam o quadrado das oposiçóes e formalizá-las na teoria quantificacional. Assim, a proposição "todo A é B", traduz-se por $\forall x(\mathrm{~A} x \rightarrow \mathrm{B} x)$; a proposição "nenhum A é B", é traduzida por $\forall x(\mathrm{~A} x \rightarrow \neg \mathrm{B} x)$; a proposição "algum A é B", é traduzida por $\square x(\mathrm{~A} x \wedge \mathrm{B} x)$; e a proposição "algum A não é $\mathrm{B}$ ”, torna-se $\square x$ $(\mathrm{A} x \wedge \neg \mathrm{B} x)(\mathrm{cf}$. MORTARI, 2001, p. 112). É por isso, que se diz que a lógica

6 GOLDSTEIN, L.; BRENNAN, A.; DEUTSCH, M.; LAU, J.F. Lógica: conceitos-chave em filosofia. Trad. Lia Levy. Porto Alegre: Artmed, 2007. 
de primeira ordem é capaz de expressar muito mais coisas que a lógica sentencial, contudo, o conjunto de operaçóes sentenciais é parte fundamental para a lógica de primeira ordem, uma se insere na outra.

Assim fundamentada, a lógica clássica possui aplicações incontáveis, porém, ainda permanece com algumas limitações. Uma das limitações é ausência de indícios temporais, e outra é a manipulação apenas de sentenças declarativas. Não se pode negar que isso é um problema da lógica clássica, visto que um dos objetivos da lógica é "o estudo dos princípios que governam qualquer tipo de raciocínio” (op.cit., p. 354). Por isso, várias lógicas não-clássicas são formuladas no século XX, sendo a mais famosa delas a lógica modal alética, que trabalha com os conceitos de 'necessidade' e 'possibilidade'.

Quando uma proposição é necessariamente verdadeira, não existe lugar para um 'é possível'. Se for necessariamente verdade que um homem não é um cão, não pode existir a possibilidade de um ente ser homem e ao mesmo tempo ser cão. Por isso, segundo Goldstein et al.(2007, p. 136), os operadores da lógica modal são interdefiníveis, ou seja um operador pode ser explicado por outro equivalente. Usa-se, como operadores da lógica modal, o símbolo ' $\square$ ' significando 'é necessário que', e o símbolo ' $\nabla$ ' significando 'é possível que’. Assim, uma verdade necessária é interdefinível por um operador de possibilidade, da seguinte forma:

$\square \alpha=\neg \diamond \neg \alpha \quad$ (é necessário que $\alpha$, é igual a: não é possível que não seja $\alpha$ )

Esses operadores modais são acrescidos à lógica clássica que já possui o cálculo com quantificadores e o cálculo sentencial, aumentando ainda mais o grau de complexidade. A ampliação provocada por essas modalidades lógicas permitiu o desenvolvimento da noção de 'mundos possíveis', que são modos de como as coisas podem ser, além, é claro, do modo como as coisas são no mundo atual. O significado de 'necessário' e 'possível' pode ser descrito da seguinte forma: $\square \alpha$ é verdadeira se $\alpha$ é verdadeira em todos os mundos possíveis; $\diamond \alpha$ é verdadeira se $\alpha$ é verdadeira em algum (ou pelo menos um) mundo possível. Com os mundos possíveis muitas ideias puderam ser percebidas de maneira mais clara admitindo a existência da possibilidade, ao inferir sobre algum argumento. 


\section{Semiótica e o percurso gerativo de sentido}

A semiótica é uma disciplina recente, rigorosa e preocupada com a produção de padrôes para descrever a universalidade da significação. Tal descrição expóe um modelo de previsibilidade aplicável a qualquer tipo de texto: verbal, não-verbal e sincrético. Focando o rigor científico, a semiótica trata as questóes de sentido sem recorrer à paráfrase, e recusando a interpretação intuitiva, impressionista e pessoal. Embora seja uma disciplina recente, o seu objeto de estudo não o é. O estudo dos signos e da significação é observado desde a antiguidade clássica com Platão, até a era medieval com Santo Agostinho e a era moderna com Locke e Kant. Sabendo da liquidez dos estudos sobre verdade, principalmente no que diz respeito à interpretação do sentido, a semiótica não tem a pretensão de investigar a verdade daquilo que é comunicado, mas apenas o simulacro da verdade, para que náo se precise recorrer a artifícios externos ao texto (cf. CORTINA e MARCHEZAN, 2007, p. 394) ${ }^{7}$.

Há uma vertente semiótica anglo-saxã, fundamentada em Charles Pierce; e há outra vertente semiótica européia baseada em Algirda Julius Greimas, lituano radicado em Paris. É nesta última vertente que concentraremos um tópico de análise. A semiótica greimasiana caracterizou-se por uma primeira fase bastante ligada à noção de forma, trazida da herança saussureana. Embora a substanciação do sujeito fosse considerada relevante, questôes relativas a este só foram consideradas na relação sujeito-objeto e não puramente no(s) sujeito(s). Pretendia-se um rigor técnico que só o estudo da forma poderia expor, pois se temia cair no subjetivismo da análise. Com isso, a forma do conteúdo foi elevada a um nível acima da forma da expressão, diferença que liberou a semiótica de estudar a semântica apenas pelos lexemas, e o semema foi priorizado na questão semântica.

Nessa primeira fase, mais preocupada em explicitar o processo significativo do texto, a semiótica foi marcada pela ênfase nos três níveis de seu percurso gerativo de sentido: o nível profundo, o nível das estruturas narrativas e o

7 CORTINA, A. e MARCHEZAN, R.C. Teoria semiótica: a questão do sentido. In: MUSSALIM, F. e BENTES, A.C. Introduçâo à Linguistica: fundamentos epistemológicos. Vol. 3, 3a ed. São Paulo: Cortez, 2007. 
nível das estruturas discursivas. Na segunda fase, o percurso gerativo mantém a sua importância, contudo os estudos da narratologia são ampliados para o estudo do sujeito, não apenas entre sujeito-objeto, mas também, para a relação entre sujeitos. Sabendo da existência de duas classes modais, o ser e o fazer, outras quatro modalidades se associam a essas: o querer, o dever, o poder e o saber. A modalidade do fazer permite uma categorização do sujeito pelo fato do sujeito realizar-se como o 'ator' no nível discursivo.

A relação entre sujeito/objeto e entre sujeitos destinador/destinatário caracteriza a tensividade que há entre eles, algo que pode desvelar uma tensão ou um relaxamento. E, voltando às classes modais do ser e do fazer, perceber-se-á que as açôes do sujeito ligam-se à modalidade do fazer, enquanto que a modalização do ser subleva o exame das paixôes. Paixão e ação estão em ligação opositiva. Essa ligação entre paixão e ação em nada se demonstra de caráter psicológico, demonstra-se em caráter ontológico. Contudo, esse caráter ontológico é apenas um auxílio para a análise do que é comunicado concretamente no discurso, e não para uma análise metafísica dos estados, como já feita por Descartes na Idade Moderna e por Aristóteles na antiguidade clássica.

\subsection{O quadrado semiótico}

Ao perceber que não existe conflito entre as fases da semiótica, existe apenas uma ampliação temática, vimos que o percurso gerativo de sentido continua presente na fase tensiva da semiótica. Esse percurso é considerado o "núcleo duro" da disciplina, e o principal elemento que se constitui no nível profundo, chamado de gramática fundamental, é o quadrado semiótico. A importância do quadrado lógico transpassa o primeiro nível conceptual, e estende-se ao nível antropomórfico e enunciativo. Na verdade, orienta qualquer etapa da descrição, como afirma Barros (2001, p. 23) ${ }^{8}$ sobre uma das funçóes do modelo quaternário:

8 BARROS, D.L.P. Teoria do discurso: fundamentos semióticos. $3^{\mathrm{a}}$ ed. São Paulo: Humanitas/ USP, 2001. 
representar as relações semânticas em sua dimensão paradigmática e propiciar-lhes a sintagmatização pelas operações orientadas, em qualquer etapa da descrição. O quadrado semiótico pertence ao nível metalinguístico da semiótica. Ressalte-se, ainda, qualquer que seja a tarefa cumprida, a eficácia heurística do quadrado, enquanto modelo de previsibilidade.

Por isso, este recurso permanece muito utilizado na Semiótica das Paixóes de Greimas e Fontanille (1993). Através do quadrado, o livro aborda as categorias de modalização (p. 42), as estruturas actanciais (p. 45), os modos de existência do sujeito (p. 52), inclusive as descrições das paixôes se servem do recurso quaternário, dentre outras coisas. Uma das diagramaçóes produzidas serve para ilustrar que os actantes sujeito e objeto podem ser tratados como categorias ao assumirem o nível narrativo. Por exemplo:

QUADRO 3 - Categorização proto-actante de Greimas e Fontanille (1993, p. 45)

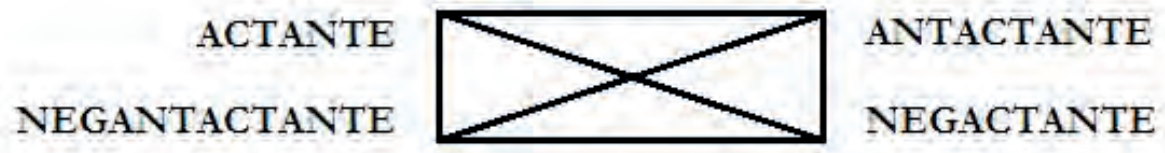

Mas, antes de conjecturar a respeito de objetos não definidos, convém demonstrar como é o funcionamento desse quadrado semiótico. Na gramática fundamental, o subcomponente taxionômico descreve o modo de existência da significação como um microssistema relacional não orientado, pois um termo sozinho não significa. De acordo com Barros (2001, p. 21), "a estrutura elementar define-se [...] como a relação que se estabelece entre dois termos objetos - um só termo não significa -, devendo a relação manifestar dupla natureza de conjunção e disjunção”. Eis a estrutura elementar concebida pelo quadrado semiótico, tal como consta em Barros (op.cit.): 
QUADRO 4 - Formalização do quadrado semiótico.

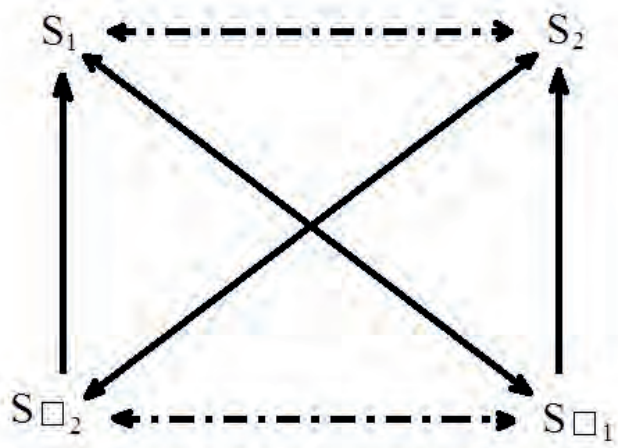

—- Relação de contrariedade

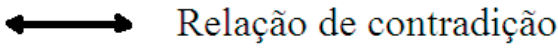

$\longrightarrow$ Relação de complementariedade

$S_{1}$ e $S_{2}$ são os termos da categoria elementar e apresentam-se em oposição por contraste. Ambos podem indicar um novo termo através da negação, levando a seus contraditórios: $\mathrm{S} \square_{1}$ e $\mathrm{S} \square_{2}{ }^{9}$. Quando se volta ao quadro 3, nota-se que 'actante' e 'antactante' são termos polares de uma mesma categoria que leva a seus contraditórios: $\mathrm{S} \square_{1}$ deve negar o actante com o termo 'negactante', enquanto, $\mathrm{S}_{2}$ deve negar o antactante com o termo 'negantactante'. Pela facilidade didática, uma relação de oposição bastante comum em compêndios de semiótica é a relação "macho-fêmea", como $S_{1}$ e $S_{2}$, gerando não-macho e não-fêmea como contraditórios. Os termos apontados pelo quadrado definem seis dimensôes dividido em dois eixos, dois esquemas e duas dêixis; junto a essas, pode-se acrescentar os conceitos de complexo e neutro, que na relação macho-fêmea entende-se a sexualidade como 'complexo' e a assexualidade como 'neutro'. Tudo isso, resulta em três geraçóes:

9 O símbolo $\square$, no texto de Barros (2001), parece representar apenas a forma quaternária. Não parece em nenhum momento, ser utilizado como o símbolo de necessitaçáo da Lógica Modal. 
$1^{\text {a }}$ geração: $S_{1}+S_{2}$ e $\mathrm{S}_{1}+\mathrm{S}_{2}$ (contrariedade)

2a geração: $S_{1}+S_{\square_{1}}$ e $S_{2}+S_{\square_{2}}$ (contradição)

3a geração: $S_{1}+S_{2}=S(S$ = complexidade $)$

$$
\mathrm{S} \square_{1}+\mathrm{S} \square_{2}=\mathrm{S} \square(\mathrm{S} \square=\text { neutralidade })
$$

Todas essas operações permitem à significação ser passível de narrativização, realizando formatos em que se negam um conteúdo e se afirmam outro ( $o p$. cit., p.23). Se pudéssemos aplicar a 3 a geração ao quadro 3, teríamos algo do tipo $\mathrm{S}_{1}+\mathrm{S}_{2}=$ atividade (termo complexo) e $\mathrm{S} \square_{1}+\mathrm{S} \square_{2}=$ inércia ou não-atividade (termo neutro). Possivelmente a aplicação dos conceitos de complexo e neutro não deva ser necessária ao quadro 3, contudo, a teoria aponta que o conteúdo é possível, o que não significa que seja útil em todos os quadros e tabelas opositivas.

\section{A pragmática}

Os termos pragmática e pragmatismo são facilmente confundíveis, pode-se dizer que estão intimamente relacionados, mas não é conveniente misturá-los de forma inadvertida, pois nem todos os temas são comuns a ambos. O pragmatismo é uma corrente filosófica estadunidense que defende que o sentido das coisas está na utilidade em que qualquer ato, objeto ou proposição gera na vida prática; foi inaugurada nas décadas finais do século XIX com o artigo How to make our ideas clear de Charles Peirce ${ }^{10}$. Já a pragmática é uma área ligada à linguística e a filosofia analítica em que o sentido daquilo que é comunicado é visto através do uso, do contexto. O termo 'pragmática' foi citado pela primeira vez no pragmatismo de Peirce, mas ganhou status de disciplina com os estudos de Grice e com os filósofos analíticos: Quine, Austin e Strawson. A pragmática é uma teoria das intenções comunicativas e dos atos de linguagem, é, nas palavras de Korta e Perry (2011, p.140) ${ }^{11}$ : "the way speakers use language in communicative situations to plan and execute utterances

10 Este filósofo também é um dos fundadores da semiótica norte-americana, e foi brevemente citado parágrafos antes. As duas vezes em que se mencionou Peirce foi para esclarecer que: a semiótica abordada não foi a de origem peirceana e a pragmática usada não é ligada, diretamente, ao pragmatismo de Peirce.

11 KORTA, K. e PERRY, J. Critical Pragmatics - An inquiry into reference and communication. Cambridge University Press, 2011. 
in the light of semantic properties, and other properties [...] that is, how speakers do things with words"12. A pragmática não se resume ao significado do ponto de vista do falante em determinado contexto, mas estuda como um enunciado significa bem mais do que aquilo que é dito, estuda também, o papel da dêixis social (os níveis de formalidade e intimidade dos papéis sociais) na influência do que é dito.

A teoria da implicatura é uma das mais importantes contribuições à pragmática. Essa teoria foi formulada pelo filósofo H.P.Grice que popularizou as implicaturas conversacionais através de suas máximas. Sabendo da importância do contexto comunicativo para a compreensão do dito, Grice (1989, p. 26-27) ${ }^{13}$ institui quatro categorias: quantidade, qualidade, relação e modo. Entre outras coisas, suas máximas relatam que a informação não deve ser excessiva, deve buscar a verdade, deve ser relevante para os participantes da enunciação e deve ter clareza.

Outro tema pragmático de grande repercussão na linguística refere-se aos atos de fala. A teoria dos atos de fala nasce com os filósofos analíticos que por sua vez são extremamente ligados à lógica formal de Frege e Russell. Austin formulou a noção de performatividade com a ideia de que 'dizer algo é fazer algo', com isso lança o livro How to do things with words em que descreve que os proferimentos possuem uma divisão em: - ato locucionário ${ }^{14}$, de natureza referencial, fonética e sintática; - ato ilocucionário, é performativo corresponde ao que é feito quando se diz algo, como prometer, anunciar, pedir, etc.; e - ato perlocucionário, de natureza indutiva, corresponde aos efeitos provocados no interlocutor ao dizer-se algo, efeitos como dúvida, constrangimento, júbilo, raiva, etc. Tais atos não ocorrem isoladamente, segundo Austin (1962, p. 98) ${ }^{15}$ eles estão relacionados entre si: "to perform a locutionary act is in gener-

12 Tradução nossa: "a forma como os falantes usam a linguagem nas situaçôes comunicativas para planejar e executar enunciados à luz das propriedades semânticas e outras propriedades [...] que é como os falantes fazem coisas com palavras".

13 GRICE, H.P. Studies in the ways of words. Cambridge, MA: Harvard University Press, 1989.

14 O termo em ingles é "locutionary", há traduçôes que usam o termo em português "locutório", e da mesma forma ilocutório e perlocutório. Não obtive nenhum critério mais específico de tradução, portanto escolhi o termo "locucionário" apenas porque é o termo usado na tradução brasileira de Searle (2002, p. 8), onde diz "força ilocucionária".

15 AUSTIN, J.L. How to do things with words. $2^{\text {nd }}$ ed. Cambridge: Havard University Press, 1975[1962]. 
al, we may say, also and eo ipso to perform an illocutionary act, as I propose to call it. Thus in performing a locutionary act we shall also be performing such an act" 16 .

\subsection{Intencionalidade e estados intencionais}

Se repararmos bem, tanto as máximas conversacionais quanto os atos de fala são temas que precisam de um sujeito que age. Talvez por isso, autores pragmáticos sejam citados com relativa frequência em trabalhos de semiótica. A necessidade de um sujeito agente aponta para a linguagem como uma ação humana. E se há ação, então há intencionalidade; é preciso que haja um sujeito intencional criando movimento de corpo que implica em ação. Além dos atos performativos, Grice também propóe uma breve teoria intencional, mas é John Searle que publica, praticamente, um tratado sobre o tema. Na pragmática, a significação pode ser apreendida através do significado das intençóes do falante $F$, da seguinte forma:

$\mathrm{U}$ meant something by uttering $\mathrm{x}$ ' is true iff', for some audience $\mathrm{A}, \mathrm{U}$ uttered $\mathrm{x}$ intending:

\section{(1) A to produce a particular response $\mathrm{r}$ \\ (2) A to think (recognize) that U intends (1) \\ (3) A to fulfill (1) on the basis of his fulfillment of (2). (GRICE, 1989, p. 92) ${ }^{18}$}

No livro Expression and Meaning, Searle retoma os trabalhos de Austin ampliando os conceitos internos à teoria dos atos de fala: declarou a força ilocucionária atuando sobre o conteúdo proposicional, descreveu as categorias de atos ilocucionários, esclareceu o que se entende por sentido literal, etc. A intencionalidade deveria estar presente nesse trabalho sobre os atos de fala, porém, como ele próprio afirmou, seus escritos sobre o tema se avolumaram

16 Tradução nossa: "realizar um ato locucionário, em geral, podemos dizer que é o eo ipso para realizar um ato ilocucionário, como proponho chamar. Assim, realizando um ato locucionário, também estaremos realizando tal ato".

$17 \mathrm{Na}$ lógica, o termo "iff” ou "sse" em português, é abreviatura da bicondicional que significa "se e somente se".

18 Tradução nossa: “ $F$ significa algo através do enunciado $x$ ' é verdadeiro sse para alguma audiência $A, F$ proferiu $x$ tencionando que: (1) $A$ produza uma resposta $r$, (2) $A$ reconheça que $F$ intencionou (1), (3) $A$ realize (1) com base na realização de (2)”. 
de tal maneira que ele preferiu compilar tudo num único volume, em uma obra à parte: o Intentionality. Assim, Searle (2002, p. 111-153) formula sua própria teoria da ação, na qual uma ação completa compreende os elementos: intenção prévia, intenção na ação, movimento de corpo e condições de satisfação. Esse modelo representa apenas a ação completa e transitiva, pois isso não funciona rigidamente, já que grande parte das açóes é realizada no momento da execução e, portanto, não possuem intenção prévia; da mesma forma, nem todas as condições de satisfação e insatisfação conseguem ser previstas em atos que ocorrem causalmente pela intenção prévia.

Tanto o modelo de ação griceano quanto o searleano necessitam de um componente mais básico dentro da intencionalidade: os estados intencionais. Searle (op.cit., p. 12) diz que "o estado Intencional ${ }^{19}$ expresso não é um mero coadjuvante da realização do ato de fala. A realização do ato de fala é necessariamente uma expressão do estado Intencional correspondente...”. Por isso, soaria estranho alguém dizer que "está chovendo, mas não acredito que esteja chovendo". Claro que é sempre possível constatar condiçôes de insinceridade como a mentira, mas, para Searle, mesmo que isso ocorra não haverá grandes alterações no estudo, pois a condição insincera simulará um conteúdo proposicional, e esse conteúdo possui uma crença correspondente. Note-se que a crença do que é expresso está ligada à proposição e não exclusivamente à psicologia do enunciador.

Descrevendo a natureza dos estados intencionais, Searle dá destaque à 'crença' e ao 'desejo' como formas básicas que se entrelaçam numa rede a formar vários estados intencionais, em outras palavras, a crença e o desejo são estados que compóem os demais estados intencionais, que por sua vez são extensionáveis em formalização lógica. Partindo para alguns exemplos, considere-se o 'temor': "alguém que tema $p$, deve acreditar que é possível que $p$ e deve querer que seja o caso que não $p$ (op.cit., p. 42); assim, temos: Temor $(p) \rightarrow$ Cren $(\diamond p) \&$ Des $(-p)$. Do mesmo modo, Searle (op.cit., p. 43-48) descreve vários outros estados intencionais: expectativa $(p) \rightarrow$ Cren (Futuro $p$ ); desapontamento $(p) \rightarrow$ Cren presente $(p) \&$ Cren passada (futuro $\sim p$ ) \&

19 Searle faz diferença entre "intenção" e "Intenção", para ele a palavra grafada com 'I' maiúsculo reflete a postura teórica de tratar o termo com o sentido de "direcionalidade". Não entramos no mérito da questáo, e adotamos o uso comum do termo. 
Des $(\sim p)$; ter prazer em que $(p) \rightarrow$ Cren $(p) \&$ Des $(p)$; Ter esperança que $(p)$ $\rightarrow \sim$ Cren $(p) \& \sim$ Cren $(\sim p) \&$ Cren $(\diamond p) \&$ Des $(p)$; remorso $(p) \rightarrow$ Cren $(p)$ $\&$ Des $(-p) \&$ Cren (sou responsável por $p$ ); etc. A intenção, no sentido estrito de tencionar algo, é considerado por Searle o caso mais difícil, o qual foi necessário dois capítulos inteiros abordando o assunto. Mesmo assim fornece uma formalização parcial da intenção:

Tencionar (eu fazer $A) \rightarrow$ Cren $(\diamond$ eu fazer $A) \&$ Des (eu fazer $A$ )

Uma das limitaçóes dessa análise reside no fato de que a Crença e o Desejo juntos são incapazes de distinguir alguns estados intencionais que são claramente diferentes. Nos casos de estar aborrecido porque $p$, estar triste que $p$ e sentir muito que $p$ são exemplos que se apresentariam, os três, com a fórmula Cren $(p) \&$ Des $(-p)$, mas obviamente não sáo os mesmos estados intencionais. Apesar disso, Searle acredita no alcance da abordagem principalmente ao se estudar as formas primárias da intencionalidade: a percepção e a ação.

\section{Considerações finais sobre a lógica nas ciências da linguagem}

As ciências, principalmente as humanas, necessitam elaborar pesquisas e teorias que sejam passíveis de formalização numa linguagem técnica, que lhes garanta o nível científico para mençôes e refutaçóes teóricas. Em princípio, essas formalizaçóes parecem complicar o que é aparentemente simples, mas é através delas que percebemos fenômenos e problemas que são ocultados pela aparência de simplicidade de alguns objetos de estudo. Há alguns anos, Oliveira $(2007 \text {, p. } 240)^{20}$ lançava o questionamento:

Se há tantas diferenças qualitativas entre um sistema lógico e as línguas naturais, por que é que há linguistas perdendo tempo tentando explicar as línguas naturais através de sistemas lógicos? A resposta, neste caso, não pode ser o compromisso ético com a ciência.

${ }^{20}$ OLIVEIRA, R.P. Formalismos na linguística: uma reflexão crítica. In: MUSSALIM, F. e BENTES, A.C. Introdução à Linguística: fundamentos epistemológicos. Vol. 3, 3a ed. São Paulo: Cortez, 2007. 
E realmente essa não é a resposta. O sistema lógico permite a descoberta de fenômenos, sistematiza as descriçóes e organiza o raciocínio em argumentos e inferências. A linguística já corrigiu erros com base no raciocínio da teoria da quantificação. A definiçẫo antiga de pronomes como "palavras que substituem o nome" é um exemplo de como os quantificadores puderam comprovar a incoerência da definiçãao, pois os pronomes nem sempre substituem o nome, servem também como indicadores de universalidade e particularidade (cf. op.cit., p. 241).

A esta altura, ficou evidente o entrelaçamento das operações lógicas com as teorias linguísticas, principalmente comparando a primeira metade deste artigo com a segunda. Não obstante convém aclararmos os tópicos fazendo as devidas conexôes entre si.

Lembrando do quadro 4 , há a representação de $S_{1}$ e $S_{2}$ como relação de elementos contrários, que é a uma relação similar a do quadro 1 entre as proposiçóes $A$ e $E$ de afirmação universal e negação universal. Lembrando dos termos que representam $S_{1}$ e $S_{2}$ no quadrado montado por Greimas (quadro 3), temos $S_{1}$ a actante e $S_{2}$ = antactante, o que é antactante senão o contrário de actante? As conexóes diagonais do quadrado semiótico representam $S_{1}$ e $\mathrm{S} \square_{1}$ como termos contraditórios, relação semelhante a descrita por Aristóteles em $D a$ Interpretação, que é representada pelas proposiçóes $A$ e $O$. No quadrado greimasiano, temos $\mathrm{S} \square_{1}=$ negactante como contraditório que nega $S_{1}=$ actante, que na descrição aristotélica, os contraditórios devem negar particularmente aquilo que é afirmado universalmente; por isso que no quadro 3 os polos inferiores do quadrado possuem o prefixo 'neg', porque precisam negar o que é afirmado nos polos superiores do quadrado. De igual modo, as relaçóes verticais e não-diagonais são complementares entre si, pois se o termo $\mathrm{S} \square_{2}=$ negantactante é contraditório a antactante, então o termo negantactante é uma informação complementar a $S_{1}=$ actante.

Apesar das semelhanças entre os quadrados e dos polos geométricos apresentarem as mesmas ideias de contrariedade e contradição, não convém criar parentescos apressados entre Greimas e Aristóteles, porque um trabalha com relaçóes universais e particulares e outro com relaçóes de sentido extraídas de um texto/discurso objeto de análise.

Os recursos lógicos da semiótica não se limitam ao quadrado, estendem-se às outras etapas do percurso gerativo. A etapa que compreende a gramática 
narrativa, por exemplo, expõe a conjunção $\mathrm{S} \cap \mathrm{O}$ e a disjunção $\mathrm{S} \cap \mathrm{O}$ que são teoremas das fórmulas do programa narrativo: $\mathrm{F}\left(\mathrm{S}_{1} \rightarrow\left(\mathrm{S}_{2} \cap \mathrm{O}_{\mathrm{v}}\right), \mathrm{F}\left(\mathrm{S}_{1} \mathrm{U}\left(\mathrm{S}_{2}\right.\right.\right.$ $\mathrm{U} \mathrm{O}_{\mathrm{v}}$ ), facilmente inteligíveis quando se domina o sistema verifuncional e o alfabeto do cálculo de predicados, já abordados itens atrás.

Falando sobre o sistema verifuncional, percebemos que este sistema lógico é fundamental para a descrição dos estados intencionais, de outra forma, como seria possível descrevê-los sem esse recurso? Searle usa conceitos consagrados:

- operação de conjunção ' $\wedge$ '/' \&' para explicar as subpartes das implicaçóes utilizadas, como no estado intencional do remorso em que sua implicação é formada pelas conjunções dos termos crença que $(p)$ e desejo que $(-p)$ e crença de que sou responsável por $p$.

- operação do condicional ' $\rightarrow$ ' para explicar o estado intencional do prazer, pois a condição de ter prazer em que $(p)$ deve implicar que exista uma crença $(p)$ e um desejo $(p)$.

- a bicondicionalidade ' $\leftrightarrow$ ' para descrever o estado intencional da expectativa, pois se é verdade que a expectativa $(p)$ implica na crença de (Futuro $p$ ), então, no sentido inverso também é verdade que a crença de (Futuro $p$ ) implica na expectativa $(p)$ de que isso se confirme.

- a lógica modal também é utilizada, dentro do sistema verifuncional, para descrever a modalização de possibilidade ' $\vartheta$ ', como no estado intencional do temor. Se alguém tem o temor $(p)$ deve possuir a crença de que seja possível ocorrer $(p)$ e possuir o desejo de que esse $(p)$ não ocorra, então $(\sim p)$.

Vários textos de semiótica foram consultados neste trabalho, e constatamos que não é comum conectar a origem do quadrado semiótico ao quadrado das oposições. Uma das principais diferenças entre eles é que o diagrama greimasiano trabalha com sememas, enquanto que o diagrama aristotélico trabalha com proposiçôes. Há também no quadrado semiótico a inclusão de uma $3^{a}$ geração que engloba os conceitos de complexidade e neutralidade, e, por tal acréscimo, visualmente o quadrado transforma-se num hexágono. As afirmaçóes que quase mencionam o quadrado aristotélico, encontramos em Fontanille e Zilberberg (2001, p. 65) 21 "não será impossível vinculá-lo ao

21 FONTANille, J. e ZILBERBERG, C. Tensão e Significação. Trad. Ivã Carlos Lopes et. al. São Paulo: Discurso Editorial: Humanitas / FFLHC / USP, 2001. 
quadrado de Apuleio, para uns, de Aristóteles, para outros"; e na asserção de Greimas e Courtés (2008, p. 400) 22 :

O quadrado semiótico pode ser comparado, com proveito, ao hexágono de R.Blanché, aos grupos de Klein e de Piaget. Inscrevese, contudo, na problemática epistemológica concernente às condições de existência e de produção da significação e, ao mesmo tempo, no domínio do fazer metodológico aplicado aos objetos linguísticos concretos: nesse particular, distinguese das construçôes lógicas ou matemáticas, independentes, na qualidade de formulaçóes de "sintaxe pura", do componente semântico. Nessas condiçóes, qualquer identificação apressada dos modelos semióticos com os lógico-matemáticos só pode ser perigosa.

Nessa última citação de Greimas e Courtés, pode-se questionar: em que momento há a ideia de proximidade com o quadrado aristotélico? Realmente não há uma menção clara, mas há uma referência a Robert Blanché. E quem conhece a teoria de Blanché sabe que o seu hexágono é uma continuação das inferências do quadrado das oposiçóes, pois se cria justamente a partir das limitaçóes desse quadrado. Quanto ao quadrado semiótico, os teóricos não se arriscam em afirmar a origem grega do diagrama, afirmam apenas que algumas comparações são possíveis. Sobre esse hexágono de Blanché, Horn (2012) ${ }^{23}$, logicista de Yale, explica que o quadrado pode apresentar uma conjunção semântica entre as proposições $I$ e $O$ formando um triângulo, outro triângulo é formado com as proposições $A$ e $E$, com isso ele re-afirma o que foi dito por seus antecessores: "For Jacoby (1950), Sesmat (1951), and especially Blanché (1952, 1953, 1969), the square and triangle in (4) can be combined to form a Hexagon of Opposition on which the diame-

22 GREIMAS, A.J. e COURTÉS, J. Dicionário de Semiótica. Trad. Alceu Dias Lima et al. São Paulo: Contexto, 2008.

23 HORN, L. Histoire d*O: Lexical Pragmatics and the Geometry of Opposition. In: BEZIAU, J. e PAVETTE, G. The square of opposition: a general framework for cognition. New York: Peter Lang edition, 2012. 
trically opposed terms are contradictories" 24 (op.cit., p. 399), de onde surgem semelhanças com os conceitos de neutralidade e complexidade demonstradas em Barros (2001).

A explicação do termo, através de Greimas e Courtés é no mínino perturbadora e ao mesmo tempo paradoxal: por que a relação com os modelos lógico-matemáticos é perigosa? A própria semiótica utiliza vários logicismos como a relação sujeito-objeto: $\mathrm{S} \cap \mathrm{O} \rightarrow \mathrm{S} \cup \mathrm{O}$, e $\mathrm{S} \cup \mathrm{O} \rightarrow \mathrm{S} \cap \mathrm{O}$; não seria isso uma sintaxe da lógica? Ao que parece, Fontanille e Zilberberg (2001, p. 65) consideram mais adequado vinculá-lo a Hegel e Lévi-Strauss, pela existência da 'tríade dialética' hegeliana formadas pelo: ser, não-ser e o devir. Greimas devia saber os riscos de abordar o seu quadrado exclusivamente de forma lógica, tanto é que ainda hoje os lógicos e os filósofos analíticos não aceitaram o quadrado semiótico (cf. MORETTI, 2012, p. 5) 25.

Através de todos esses mecanismos de formalização, verificamos que na ciência linguística várias disciplinas não-formalistas estão repletas de rigor científico. O raciocínio lógico-matemático ajuda na continuidade teórica e nas réplicas de contra-argumentação acadêmica. A escolha de apenas um tópico da corrente pragmática e um tópico da corrente semiótica deveu-se à natureza resumida do presente trabalho. $\mathrm{O}$ desconhecimento dos conceitos lógicos não prejudica a compreensão geral das teorias abordadas aqui, mas facilita a compreensão do tratamento que é dado aos termos estudados. Os fundamentos lógicos nas teorias linguísticas são incontáveis, encontra-se lógica no estruturalismo de Saussure, no gerativismo de Chomsky, no funcionalismo de Halliday, no cognitivismo de Fauconnier, entre outros. Este artigo serve apenas como uma pequena vitrine da infinita possibilidade deste tema.

24 Tradução: "para Jacoby (1950), Sesmat (1951), e especialmente Blanché (1952, 1953, 1969), o quadrado e o triângulo podem ser combinados para formar um Hexágono da Oposição sobre o qual termos opostos diametricamente são contraditórios”.

25 MORETTI, Alessio. "Why the logical hexagon?”. Logica Universallis. Basileia: Springer Basel, 2012. 
Costa Jr., Daniel Felix.

194 Lógica em linguística: o quadrado semiótico e os estados intencionais da pragmática

\title{
LOGIC IN LINGUISTICS: SEMIOTIC SQUARE AND PRAGMATIC INTENTIONAL STATES
}

\begin{abstract}
Some linguistic theories are filled with logical terms and operators. As examples we chose two areas - Semiotics and Pragmatics - and one subject in each of them: the semiotic square and the intentional states. Although unfamiliarity of logic operations does not affect the general understanding of the subject, it complicates the understanding of the treatment that is given to the terms.
\end{abstract}

KEYWORDS: Semiotic Square; Intentionality; Logic.

Recebido em: 02/07/2012

Aprovado em: 06/02/2013 